\section{When will we learn to love complaints?}

\author{
John Launer
}

I have just made a complaint to an electricity company. We recently moved house, changed our supplier, and needed to pay off a small final sum to the company. Because of a glitch in their online payment system, it proved impossible to do this. After receiving a threat to send bailiffs round, I finally managed to speak to someone in the debts department, and paid the bill. I also suggested they should change their system to save customers and the company unnecessary trouble and expense. The woman I spoke to was courteous, patient, and clearly well trained to deal with complaints. She explained why their system was not geared for new householders. However, she was completely uninterested in my suggestion about changing it. Rather than pressing my point, I wished her a good day and ended the call. The conversation led me to think about complaints, and how people generally deal with them.

Complaints about the health service have been in the news in the United Kingdom. Last year, the Francis Report into poor care at the Mid Staffordshire Trust identified a systemic failure to hear to the complaints of patients and their families, or to respond to ones from their own staff..$^{1}$ Similarly, a recent parliamentary committee has described a 'culture of denial' across the NHS as a whole, and a 'toxic cocktail' relating to complaints, with the public reluctant to express their concerns, and defensiveness on the part of services in addressing them. ${ }^{2}$ It is easy to imagine that this defensiveness may sometimes take the form of rudeness or even anger on the part of health service personnel. No doubt this does occur, but I suspect that in most cases it takes a subtler form, more like the behaviour of the woman at the electricity company. In general, our attitude when dealing with the public can probably be summed up as follows:

- I need to listen to complaints and pacify the people who make them

Correspondence to: Dr John Launer, Faculty Development, Health Education North West London, Stewart House, 32 Russell Square, London WC1B 5DN, UK; john.launer@londondeanery.nhs.uk
- It is my duty to explain why my organisation does things in a particular way

- If people suffer because of the system, they are exceptions and the system itself probably does not need to be changed

- If the system does need to be changed, I do not know who is responsible for this, or how to find out

- If I do know who is responsible, I doubt if they will be interested in the problem, or want to do anything about it

- If people persist in complaining after I have given them an explanation, they do not really understand my role and they are being difficult.

\section{UNREMARKABLE RESPONSE}

In a classic book, the sociologist Eliot Mishler described what he called the 'unremarkable medical interview.' In it, the doctor goes exactly through the routine learned at medical school and appears to be behaving professionally, but entirely fails to engage with the patient's own wishes or purposes in the consultation. ${ }^{3}$ By analogy, I would like to propose that we should call our general reaction to complaints, like the one I have characterised above, the 'unremarkable response.' When giving this kind of response, we feel we are behaving impeccably. Implicitly or explicitly, our organisations encourage us to react in this way. Our managers may even congratulate us for doing so. Yet it is insidious, and potentially catastrophic.

We know from research that at least half of all complaints to hospitals turn out to have a justifiable basis and a genuine need for redress. ${ }^{4}$ We also know that many complainants are primarily seeking not an apology or compensation (although these may be necessary) but an assurance that other patients in future will not suffer in the same way. People who complain may be making a moral choice to try and help the organisation function in more effective and cost-efficient ways, and achieve a better relationship with its clients. They may be doing this as an alternative to hostile action including litigation. In many cases, the information they could give us would actually help us to improve the care we offer. In spite of this, the 'unremarkable response' effectively paralyses all such attempts. While we may feel we have done a good job in calming someone down, the patient has actually given up trying to influence us and cannot be bothered to continue. This probably gets complainants off our backs for ninety per cent of the time, but it allows us to carry on repeating the same errors or perpetuating the same dysfunctional systems.

Over thirty years since Mishler first described it, the 'unremarkable interview' probably remains common in much of the medical world. By the same token, it would be unrealistic to expect that the 'unremarkable response' to complaints can be eradicated easily. As the parliamentary committee has suggested, changes within health service organisations could no doubt encourage staff to behave differently. These include training in the positive handling of complaints, assigning the most capable people in the organisation to respond to them, and introducing systems of escalation that help the organisation learn to from them. Better modelling by leaders and government in their own response to complaints from those lower down in the hierarchy would certainly help. Ultimately, however, it will depend on individual and attitudinal change. We have to discover how to monitor our own reactions to complaints, whatever our roles, and challenge the automatic way we offer the 'unremarkable response'. In the end, we will need to learn to love complaints.

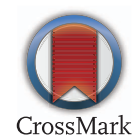

To cite Launer J. Postgrad Med J 2014;90:362.

Postgrad Med J 2014;90:362.

doi:10.1136/postgradmedj-2014-132737

\section{REFERENCES}

1 Francis R. Report of the Mid Staffordshire NHS Foundation Trust Public Inquiry. London: Stationery Office, 2013.

2 House of Commons. Public Administration Committee - Twelfth Report. 26 Mar 2014. www.publications. parliament.uk/pa/cm201314/cmselect/cmpubadm/229/ 22902.htm. (accessed 18 Apr 2014).

3 Mishler EG. The Discourse of Medicine: Dialectics of Medical Interviews. Connecticut: Praeger Publishers, 1985.

4 Pukk-Harenstam K, Ask J, Brommels M, et al. Analysis of 23,364 patient-generated, physician reviewed malpractice claims from a non-tort, blame free, national patient insurance system: lessons learned from Sweden. Qual Saf Health Care 2008;17:259-63 